\title{
Experiences of graduate registered nurses in aged care: a case study.(Report)
}

Fussell, Bridget, Fran McInerney, and Elizabeth Patterson. "Experiences of graduate registered nurses in aged care: a case study." Contemporary Nurse 33.2 (2009): 210+. Health Reference Center Academic. Web. 22 Feb. 2010.

Document URL

http://find.galegroup.com.libraryproxy.griffith.edu.au/gtx/infomark.do?\&contentSet=IAC-

Documents\&type=retrieve\&tabID=T002\&prodId=HRCA\&docId=A214205455\&source=gale\&srcprod=HRCA\&userGroupName=griffith\&version=1.0

\begin{abstract}
:
The number of Registered Nurses (RNs) working in aged care is declining, with few new RNs choosing aged care in their graduate year. This paper describes a study exploring 11 female graduate RNs' experiences of working in an aged care setting in Victoria, Australia to assist in informing recruitment and retention strategies in aged care. Semi-structured interviews were undertaken and thematically analysed using open coding. This paper presents findings related to the themes of 'free choice or allocated to aged care' 'reasons for graduate choices', 'nature of aged care: a match or mismatch for graduates', 'lack of professional support for graduate RNs in aged care' and 'role confusion'. Findings supported the recruitment of graduate RNs with an initial interest in aged care into the sector. A clearer definition of the new graduate RN's role in aged care and a standardised graduate program may assist in increasing retention of such nurses in the future.
\end{abstract}

Keywords: nursing; aged care; graduates; case study

Full Text:COPYRIGHT 2009 eContent Management Pty Ltd.

\section{INTRODUCTION}

This study responds to the impending lack of Registered Nurses (RNs, referred to as RN Division One in Victoria) to care for the nation's elderly. The shortage of qualified aged care nurses has occurred at a time when the demand for aged care services is increasing. Previous studies have identified that the majority of new graduate RNs choose not to work in aged care (Happell, 1999; Moyle, 2003). However, little is known about the experiences of new graduate RNs who accept a position in the aged care setting in their graduate year. This study was conducted to gain insight into the experiences of new graduate RNs from a diverse range of aged care settings in metropolitan and regional Victoria in order to better inform future recruitment and retention strategies. Semi-structured interviews, using questions derived from the literature, were used to elicit the new graduate RNs' experiences of aged care nursing. Comparative analysis of participants' responses provides a deeper understanding of the issues impacting on their experiences.

\section{BACKGROUND}

Demographic and policy changes have impacted heavily on both service providers and consumers of residential aged care facilities (RACFs) in Australia. The national introduction of the 'Ageing in Place' policy, an objective of the Commonwealth's Aged Care Act, 1997, encouraged and enabled older people to be supported with services to assist them to remain in the community for as long as possible (Aged Care Act, 1997 cited in Commonwealth Department of Health and Ageing, 2002). Consequently, those who live in RACFs have a higher degree of dependency and frailty than previously, with $86 \%$ of such residents assessed as being high-care status in 2006 (Australian Institute of Health and Welfare, 2007).

The need for an increased number of RNs with specialised aged care training and nurse specialist entitlement has been emphasised in several papers (Ford \& McCormick, 2000; Illefe \& Kennerson, 1995; King, 1995; Moyle \& Kellett, 1996; Stolley, Buckwatelter, \& Harper, 1995 cited in Pearson et al., 2001). The importance of recognition of qualifications, provision of opportunities for professional development, and structured career progression within the aged care sector is essential in retaining qualified staff and recruiting new nurses to the field (Pearson et al., 2001). To this end, the Aged Care Nursing Scholarship Scheme, an Australian Government initiative, was initiated to encourage people to enter aged care nursing and increase the skills of nurses working in the aged care sector, by the provision of undergraduate aged care nursing scholarships and post graduate education support (Senate Community Affairs References Committee, 2005). The effects of such financial incentives are yet to be seen.

The overall number of RNs working in aged care is declining (Senate Community Affairs References Committee, 2005). A review of the aged care nursing work force revealed that only $18 \%$ of RNs working in this area were permanent full-time employees (Richardson \& Martin, 2004). Additionally, inferred retirement rates found that $37 \%$ of the 2002 aged care nursing workforce would retire over the next ten years, compared with $26 \%$ in other spheres of nursing (Australian Health Workforce Advisory Committee, 2004). Finally, the Australian Nursing Federation (ANF) (Victoria) commented that '[in] Victoria the skills mix of RNs to residents had fallen from an average of 1 RN to 30 residents across all shifts in 1997 to 1 RN to 60 residents during the day, out to $1 \mathrm{RN}$ to 90 or 120 at the evening and night shift' (Senate Community Affairs References Committee, 2005, s.2.13).

These workforce issues persist in the context of an increasing acuity of older people in RACFs and there is concern that it will become increasingly difficult to find the number and quality of staff required to care for a growing number of increasingly dependant elders. In 2007, as part of a national response to current needs and projected increases in demand for RN graduates by the Australian Government (Karmel \& Li, 2002), 5100 new undergraduate nursing places were offered over five years. Several studies however, indicate that the majority of graduate RNs choose not to work in aged care (Happell, 1999, 2002; Stevens \& Crouch, 1995; Stevens \& Dulhunty, 1992), suggesting that this initiative is unlikely to have a great impact on recruitment of nurses into this sector.

Common themes addressing the reluctance of undergraduate nursing students to work in aged care include ageism, the perceived lack of status of aged care work, the poor image of aged care nursing, and the perceived lack of excitement associated with non-acute nursing (Happell, 1999, 2002; Moyle, 2003). Furthermore, the literature suggests that graduate RNs' career preferences and attitudes are formed during their graduate year (Hayes et al., 2006). Overcoming difficulties during this year is suggested to be vital for the professional development of nurses and crucial to their retention (Victorian Government Department of Human Services, 2003). It is likely to be extremely important for the ongoing presence of RNs in the sector that graduate nurses working in aged care have a positive experience (Hayes et al., 2006).

The quality of care provided in the aged care area relies on its ability to attract motivated and interested nurses who consider working with the elderly to be a worthy and viable career. To date, there has been little research providing insights into the factors motivating graduate RNs to work in aged care. The aim of this study was to gain a better understanding of graduate RNs' experiences of working in aged care settings in Victoria, Australia, to assist in informing recruitment and retention strategies. This study has the potential to inform those stakeholders who hope to gain an understanding of what attracts and retains RNs into this sector.

METHOD 
This study was conducted via a case study approach using naturalistic inquiry to better understand the professional life world of graduate RNs in the aged care setting. A case study, defined by Polit and Beck (2006, p. 496) as 'a thorough, in-depth analysis of an individual, group, institution, or other social unit', was employed as the method of inquiry to provide in-depth insights into the individual and collective issues confronting graduate nurses in their natural work setting. A case study method was deemed appropriate for this study, as the issues surrounding the experience of graduate RNs in aged care entail multiple factors which are difficult or impossible to disentangle into their constituent parts (Payne, Field, Rolls, Hawker, \& Kerr, 2007), and the Principal Researcher (PR) had little control over confounding or other variables (Yin, 2003). The intention of this case study was to provide a rigorous analysis of a number of graduate RNs' experiences within a real-life context, which is particularly important when both the boundaries between the context (aged care nursing) and the phenomena (new graduate) are not clear (Yin, 2003), and multiple perspectives are required (Walshe, Caress, Chew-Graham, \& Todd, 2005). This case study was of both instrumental and intrinsic interest to stakeholders; instrumentally, to gain a greater understanding of the larger issues of recruitment and retention of graduate RNs into aged care areas, and intrinsically to provide insights into the experiences of graduate RNs working in this sector.

Sample

Following approval from the Griffith University Human Research Ethics Committee (Number NRS/26/06/HREC), a purposeful sample of 11 female participants from six different aged care facilities from both metropolitan and regional Victoria was recruited through the Post Graduate Medical Council of Victoria (PMCV) database. No male participants elected to participate in the study. The PMCV computer matching is a mathematical process that matches the preferences of both hospitals and candidates (Post Graduate Medical Council of Victoria, 2003). Purposive sampling allowed for greater clarity on the characteristics of the 'population' from which the cases were selected (Denscombe 2003 cited in Payne et al., 2007), and the multiple sites allowed for a range of perspectives. In 2006, the PMCV had 124 hospitals listed throughout Victoria, of which 55 included an aged care rotation as part of the graduate year. These 55 facilities offered clinical care areas that specifically catered to patients aged 65 years and over, ranging from nursing home accommodation (RACFs) to aged care rehabilitation centres, and Geriatric Evaluation and Management (GEM) units.

Eleven female participants, aged 20-50, who had been working as graduate RNs in aged care facilities (2 GEM units, 3 Rehabilitation, 6 RACFs) were recruited into the study. All participants in the sample had been working in one of these facilities for 4-10 months at the time of data collection. All participants had completed a Bachelor of Nursing course in the previous year, and eight of the eleven participants had previous experience working in an aged care facility prior to graduating with a Bachelor of Nursing (Refer Table 1). The sample size was not pre-determined, and further participants were selected based on the information needs evolving from the findings (Polit \& Beck, 2006). When no new data emerged through further data collection and the themes and categories became repetitive, saturation was achieved and no further participants were recruited (Beanland, Schneider, Lo Biondo-Wood, \& Haber, 1999).

Data collection

Data were collected using semi-structured interviews consisting of broad and more focused questions around the participants' experience of aged care since graduation. These questions emerged from a review of literature, in particular previous studies investigating factors influencing recruitment and retention of new graduate RNs into aged care (Fagerberg, Ekman, \& Ericsson, 1997; Happell, 1999, 2002; Moyle, 2003; Nielsen, 1999; Palese, Tosatto, Borghi, \& Maura, 2007; Stevens \& Crouch, 1995; Stevens \& Dulhunty, 1992). Other questions arose from issues raised by participants. The flexible nature of qualitative design allowed the interviewer to exclude questions that had been unproductive in meeting the aims of the research and focus attention on areas of particular importance (Lofland \& Lofland, 1984). All interviews were conducted over the telephone and lasted between 30 and 45 minutes.

\section{Data analysis}

The PR transcribed interview recordings verbatim and then analysed the data using the constant comparative method (Chenitz \& Swanson, 1986), involving reading and re-reading the transcripts in search of meaning and insight. This assisted her to become immersed in the data and sensitive to important issues raised by the participants (Holloway \& Wheeler, 2002). Cross-case comparisons were then made to identify and explore commonalities and differences (Payne et al., 2007). Thematic analyses of the data were undertaken using open coding (Strauss \& Corbin, 1990). Significant codes were pursued as they emerged and each transcript was examined in detail and the data were then grouped according to identifiable themes. Major categories were identified and relationships among them detailed. To ensure that the analysis of the interviews was not merely a product of the 'observer's worldview, disciplinary assumptions, theoretical perspectives and research interest' (Charmaz, 1995, p. 32), all participants were contacted by the PR, whose initial interpretations were clarified and validated by each participant. Lincoln and Guba (1985) refer to this practice as 'member checks' which provided an opportunity for participants to recognise themselves, their words and ideas and to understand and accept the researcher's analysis (Press, 2005).

Table 1 summarises the characteristics of the participants.

\section{FINDINGS}

Several themes emerged from the thematic analysis of the data. This paper presents findings related to the themes 'free choice or allocated to aged care' 'reasons for graduate choices', 'nature of aged care: a match or mismatch for graduates' which contains two dimensions: 'long-term care' and 'lack of medical technology in aged care', 'lack of professional support for graduate RNs in aged care' and 'role confusion'.

\section{FREE CHOICE OR ALLOCATED TO AGED CARE?}

This theme illustrates the graduate RNs' experience of being offered and accepting a rotation through an aged care facility as part of their graduate program. Only four of the eleven participants had expressed a desire to work in aged care during the interview process for their graduate year position. While most participants felt that they clearly stated their workplace preferences during this process, for seven participants their requests were not acted upon, and they felt disempowered:

I think somewhere in the interview I even said that I don't want to work in aged care and then I got aged care ... so I was pretty upset at the time really (Claire).

I didn't' really pick aged care as a preference. I just got it so I had no choice (Helen).

It is not evident from the findings of this study if graduate RNs declined taking positions if they included an aged care rotation, as all participants in this study had accepted this placement. However, it is clear that several participants who did accept graduate RN positions that included aged care did so reluctantly:

Well I guess ... none of us went there willingly we just went there because we were told we had to (Fran).

Several participants expressed feelings of disappointment when they were offered a placement in an aged care area: 
It was offered in the graduate nurse program ... you don't really get a choice. It wouldn't be something that I would have chosen (Cath).

\section{REASONS FOR GRADUATE CHOICES}

The main reason for these graduate RNs not wanting to work in aged care appeared to be their desire to work in the acute care setting. Several participants perceived that the acute care setting would provide them with greater opportunities to develop the clinical skills that they had learnt in their undergraduate training. Aged care was not seen as an area that could provide opportunities to practice and enhance their acute care skills, which appeared to be highly valued by the majority of participants:

A lot of undergraduate nurses have said to me 'why would you want to go into aged care nursing? It's old people who really don't need the acute nursing skills that you've acquired' (Lara).

Several also described that they had worked in aged care as PCAs or Enrolled Nurses during their undergraduate education. They felt that this experience had provided them with enough opportunities to learn from the aged care environment and now wanted to experience other areas of nursing:

In your grad[uate] year you want to learn as much as you can in that ... time and a lot of nursing students have worked in aged care through their uni days as a Div Two [RN Division Two] or something and they probably think they know that area [and] they want to try different areas in their grad year instead of doing aged care. There's a lot more exciting things (Marie).

Conversely, four participants asserted their clear desire to work in aged care during their graduate year. These nurses described that their initial decision to enter a Bachelor of Nursing was based on their experiences working in aged care as either ENs or PCAs:

When I went back to do the degree I had no intention of ever going into acute so my whole uni thing ... in my head was focused towards aged care (Toni).

These participants had a strong bond with the aged care area which influenced their workplace choice at the commencement of their graduate year:

Because I like aged care nursing and I decided to give it a go in my grad rotation and I never regretted it (Lara).

No participants under the age of 30 chose to spend their graduate year in aged care, while three of the four participants aged over 30 did choose this rotation. While this study sample is small and not designed to be generalisable, this characteristic was nonetheless interesting, and was reinforced by participants' observations that maturity and life experience were required to work in aged care:

I find that older staff members don't mind working with the elderly whereas the young ones want the A and E experience with the more clinical stuff I suppose (Anna).

This sentiment was shared by some of the younger graduate RNs, who expressed their desire to gain acute care experience in their graduate year and their belief that aged care practice was for later in life:

I think aged care nurses are the older generation amongst nurses and they go there after they have done all the other hospital things, the more acute things, then they go into aged care (Renee).

\section{NATURE OF AGED CARE: A MATCH OR MISMATCH FOR GRADUATES}

The graduate RNs' expectations and goals for their graduate year appeared to deeply influence their satisfaction associated with working in aged care. The data suggests that the aged care work environment did not meet the expectations and goals of some graduate RNs. This section has been divided into two dimensions: the first deals with the graduate RNs' feelings about the role of the RN in long-term care of older adults. The second dimension addresses the use of medical technology and the graduate RNs' perceptions of the nursing skills required to work as an RN in aged care.

Long-term care

Participants described both positive and negative aspects associated with caring for long-term patients or residents. It appears that the graduate RNs who wanted to work in aged care had a greater level of satisfaction associated with caring for patients over a longer period of time than those who wanted acute nursing experience with its higher client turnover:

In aged care nursing you've got their whole care plan and you know them, whereas in the acute setting they are in for a few days and then they are gone (Lara).

These graduates did not want to focus on a 'biomedical' model of nursing care. They were interested in looking after 'the person' rather than 'the disease', and found that aged care was able to meet their graduate year objectives:

Acute [care nursing] doesn't interest me at all I think it's cold. I think that having worked there as well that nurses in the acute setting are more disease focused. They forget about the person and focus on diagnosis. But I think there's more. You can't always put a bandaid on something (Toni).

However, caring for long-term patients or residents was a source of stress for several graduate RNs who felt that they should be learning in a fast-paced environment, with exposure to acutely unwell patients and high patient turnover. These participants felt that the type of work that they were doing in aged care was not providing them with adequate opportunities to experience a variety of patient issues and diseases.

I wasn't learning a lot there. It was a rehab[ilitation] so people were pretty stable; where I am at now is a surgical placement and it is very busy ... lots to learn every day? (Helen).

Participants also expressed frustration that they were looking after the same patients or residents every day, and their ability to learn new things from these patients declined the longer they were there. The participants who did not choose to work in aged care expressed that the work was repetitive and routine:

Sometimes I get sick of the same routine everyday. I would know from one day to the next that I would have patients that would be the same from the day before (Marie).

Lack of medical technology in aged care

Several participants described a lack of visible medical technical and clinical nursing skills in the long-term aged care setting, and expressed anxiety 
about this. These participants were keen to develop their acute care skills, and regarded caring for people in a longer term capacity as not meeting these objectives during their graduate year. Participants who wanted to work in aged care felt that the lack of medical technology was a deterrent for others:

We're not playing with IVs [intravenous therapy] where some of the kids would see that as glamorous, the drugs and the doctors and all the fancy equipment ... but there is so much more involved than that [in nursing] (Toni).

Graduate RNs who had not chosen an aged care rotation expressed their regard for and enjoyment of working with medical technology:

I am still interested in acute nursing um ... I still like the challenge ... and I like all the technical stuff and ... just like being challenged with all the technical stuff and I don't find that I get enough of that in aged care (Claire).

I like all surgical things, all the acute. I think it is more task orientated on the surgical ward, which I think I learn better from and enjoy more, so that's why I want to go back to surgical (Renee).

At the same time, some participants appreciated the additional skills that they could develop to nurse someone without the use of technical equipment. For example, one participant explained that the assessment of patients without the aid of medical technology was a valuable skill that she developed during her time as a graduate $\mathrm{RN}$ in aged care:

I guess I learnt a bit more patient assessment skills, being able to look at a patient and kind of know that something is wrong whereas on a ward we had everyone kind of hooked up to monitors or had obs [vital signs] at least four hourly, whereas [in aged care] their obs are once a day so you've got to pick up on other signs (Claire).

However, in general the lack of medical technology in aged care was a factor that negatively influenced the appeal associated with working in the area. For several graduate RNs, their time in this sector made them feel that they were missing out on opportunities to develop their technical nursing skills. Therefore, aged care was seen as an area that restricted their professional development:

I am not feeling as confident, as I feel that after 6 months in aged care that I have forgotten things. Because I only had the 6 months working in acute [care] and I feel like I could have forgotten things and I am back at the start a bit. It'll come back to me I'm sure but I feel like it has kind of slowed me down a bit (Marie).

\section{LACK OF PROFESSIONAL SUPPORT FOR GRADUATE RNS IN AGED CARE}

Some participants expressed that they had limited support during their aged care rotation, with the level of support differing depending on the type of aged care facility. For those in larger rehabilitation centres, the issue of isolation from other RNs was minimal. However, for those whose placement was in the RACF sector, the number of RNs was less. Some participants expressed that at times they felt they were left to their own devices, which was not always optimal for either their learning experience or the quality of care provided to residents:

Depending on who the nurse in charge was the manager would often do the drug round and you wouldn't see them for the rest of the day and I wasn't really told what my responsibilities were as the second Division One nurse and there were other times there would be somebody on that was the nurse in charge who would really guide you a lot better (Cath).

Participants observed that the ENs were expected to provide support that at times was inadequate for the graduate RN and beyond the EN's scope of practice:

Usually I was put on with at least one Div One nurse and some of them completely left You ... even when I asked for help um some of them refused to help me and told me to take a Div Two who wasn't actually qualified to put in a catheter or something like that and I had to sort of fumble my way through the whole thing ... (Cath).

All participants appeared to value strongly the ability to develop professionally during their graduate year. Most identified a lack of education sessions and professional development opportunities in aged care, and several commented that this was evidenced by an identifiable lack of inservice education sessions during their aged care rotation. All participants expressed that they valued in-service education and felt disappointed at this lack. Several compared the number of education opportunities that they could attend in their other rotations:

I think I like the in-services. They are quite informative. They should have more of them because I don't remember having that many when I was in aged care (Helen).

\section{ROLE CONFUSION}

Most participants expressed that they were unsure of their role as a new RN when they started their aged care rotation. Confusion amongst aged care nursing staff regarding the role of the graduate RN lead to further uncertainty about their appropriate level of responsibility. Consequently, some participants reported taking on more responsibility than they were comfortable with, while others felt constrained in their role, with limited responsibility and opportunities to practise as an RN. Two participants felt that they had a good understanding of their role as an RN in aged care. Both of these participants had worked as ENs prior to taking a graduate RN position, and both continued in the workplace that they had worked in prior to their graduate year. These participants described their graduate rotation in aged care as an enjoyable experience that offered very good opportunities to practice their leadership skills:

If they [the residents] want to know something they will come to you ... they don't like to go to the PCAs or the Div Twos [EN] they like to come to you and you can sort of give them the answer straight away (Lara).

However, for the majority of participants there were issues of role confusion. One participant felt that the RNs in aged care were unsure of the graduate RN role and initially confused her with a student:

Initially they would treat you just like a student and kept calling you a student and this and that and you're just like 'no I'm a nurse' (Claire).

Another area of role confusion was the lack of understanding from the ENs with regard to the role of the new graduate RN. Some participants stated that the ENs expected too much from them. For example:

I think a lot of Div Twos [ENs] didn't know what we could do and they had not had a lot of experience of grads and a few of them expect a lot more of you when you are first starting than what you know because they think 'oh she's a Div One' but you are pretty fresh so they could be more educated to help you out a bit more at times (Marie). 
Conversely, other participants felt that the ENs considered them to be too junior and would not disclose information about patients; instead reporting to the nurse-in-charge:

I suppose it has been good working with Div Twos but then you can get the occasional one that won't report to you or anything like that ... so that's made it difficult (Renee).

One participant described her experience of role change from PCA to an RN, and the role confusion that this caused for her colleagues. It appears that the graduate RN had to 'prove themselves' before they would gain trust from the PCAs and ENs:

They [PCAs and Enrolled Nurses at RACF] told me this after a couple of months. They said 'we were a little bit apprehensive because you are a graduate and we really didn't know how we were supposed to look up to you because you were a PCA' um ... but after they could see that I was actually quite competent at what I was doing they were fine ... they had no qualms about coming up to me and saying 'can you come and have a look at this person', 'we need to find out about this' and they were fine (Lara).

\section{DISCUSSION}

This study was conducted to explore the experiences of graduate RNs working in settings designed to cater for the care needs of older adults. Several studies have investigated the experiences of graduate RNs in general. This study replicates and confirms several of these findings, but identifies further specific issues effecting graduate RNs working in aged care contexts.

The majority of participants in this study would not have chosen to work in aged care. These findings concur with Nielsen (1999) who also investigated how new graduate RNs felt when they realised that they had a rotation in aged care. Those findings revealed that 44 of the 49 respondents reported being indifferent to disappointed with the aged care placement and only five indicated any excitement. Palese et al. (2007) identified that most graduate RNs base their decision on where they would like to work in their graduate year on two major factors: patient typology and their ability to perform technical nursing skills, which resonated with this study's findings. Palese et al. (2007) and this study identified that most participants preferred to take a graduate RN position in areas with acutely unwell medical or surgical patients in an acute care setting as opposed to elderly patients requiring rehabilitation or long-term care. Previous studies have identified that graduate RNs have strong preconceived ideas about the most desirable clinical area for their graduate year, with most selecting acute hospital settings and few choosing to work in long-term areas or aged care (Fagerberg et al., 1997; Happell, 1999; Nielsen, 1999; Palese et al., 2007; Stevens \& Dalhuntly, 1992).

Most participants in this study felt that they had clearly expressed which areas they would like to work in during the recruitment phase. However, the recruitment process for graduate RNs did not appear to acknowledge their work area preferences, and participants in this study were sent to aged care areas despite, at times, their explicit reluctance. Palese et al. (2007) support the finding that during the interview process graduate RNs clearly state their clinical practice area preferences. The findings suggest that graduate RNs may be a vulnerable group in the nursing workforce and consequently may possibly be used to fill areas that are difficult to recruit RNs into. Workforce pressures notwithstanding, such decisions, particularly in the context of poor resourcing of learning needs as identified here, may have deleterious consequences for ongoing recruitment and retention.

The data reveal that a small number of graduate RNs do wish to work in long-term aged care. This study suggests that those who choose to work in aged have had a long-term desire to work in this setting. The findings also indicate that this small cohort of participants had a desire to develop their skills in aged care, and were less inspired to work in areas with curative and technological emphases. However, the impact of previous experiences of working in an aged care facility when an undergraduate could also have a negative impact on recruitment of graduate RNs into the area; several participants in this study with previous experience did not want to return to the aged care area in their graduate year. Happell (2002) also identified that part-time employment of student nurses as PCAs in RACFs can further influence negative attitudes toward aged care, with approximately $25 \%$ of the reasons given by students for ranking working with older people as their least preferred option referring to previous or current experience working in an aged care setting.

Most participants in this study placed a high value on working in an area that provided them with the opportunity to utilise the knowledge and skills obtained during their undergraduate education. This is supported by the findings of Elderkin (2005) who surveyed 78 critical care course graduate RNs and identified that the most important factors contributing to retention in the critical care area were the nature of the work and the constant learning provided in the critical care environment. The data in this study lends support to previous findings that undergraduate nursing education places greater emphasis on medical and other technology, and decreased emphasis on care (Happell, 2002; Stevens \& Crouch, 1995). It is inconclusive from both this study and the related literature however, whether an increase in aged care content would increase the recruitment of new graduate RNs into aged care. The provision of an aged care curriculum in undergraduate education to improve attitudes and recruitment of undergraduate RNs is supported by several studies (Aday \& Campbell, 1995; Lookinland \& Anson, 1995; Robinson \& Cubit, 2007). However, several other studies have identified that increased aged care education makes no significant change to the attitudes and work preferences of nursing students (Carmel, Cwikel, \& Galinsky, 1992; Dellasega \& Curriero, 1991; Greenhill \& Baker, 1986; Happell, 1999).

Aged care appeared to be considered as an area that provided limited scope to consolidate and develop 'technical' nursing skills, which was unsatisfactory for the majority of participants. The graduate RN's role in aged care was described in this study as repetitive, monotonous, mundane and task orientated. Most participants felt that a large part of their day was consumed by performing tasks, such as medication administration for a large number of patients and assisting with patients' or residents' hygiene needs. For the majority of participants this 'routine' work created decreased work satisfaction. Most participants described a greater sense of satisfaction and achievement associated with work performed in acute care. The acuity and constant turnover of patients in the acute sector provided an environment of constant learning and stimulation that was more satisfying for the majority of participants.

Participants in this study who did want to work in aged care found the work satisfying, fulfilling and worthwhile. These participants had difficulty defining the specialist skills required for aged care, describing communication, developing a deeper relationship with patients or residents, and more 'subtle' skills. These 'invisible' aspects of nursing care are difficult to capture (Royal College of Nursing, 1996 cited in Pearson, 2003) and therefore may be difficult to measure and value. The participants who enjoyed working in aged care felt frustrated that a higher value and status is placed on the work performed by RNs in acute care areas. Their concerns are supported by sentiments in the literature that 'caring' as the fundamental basis of nursing, will be eroded in favour of more 'techno-medical' activities (Castledine, 1995; Denner, 1995; McAlister \& Chiam, 1995 cited in Rushforth \& Glasper, 1999). This has also been described in previous studies as the 'care' versus 'cure' phenomenon, whereby graduate RNs prefer to work in areas where there is greater emphasis on cure rather than care (Palese et al., 2007; Ring, 2002; Stevens \& Dalhuntly, 1992).

This study identified that most participants described a greater level of educational and professional support in the acute care setting in comparison to the aged care sector. The private and aged care sectors have been criticised for their limited provision of graduate programs (Parliament of Australia Senate, 2002) in the past, and it appears that some graduate RNs are still experiencing a substandard transition in the aged care area. This may have contributed to several graduates identifying a more satisfying transition in the acute care setting, and more generally to reduced graduate retention in aged care.

\section{IMPLICATIONS AND RECOMMENDATIONS}

The insights offered by this study have implications for both recruitment strategies employed to select graduate RNs for the aged care area and the 
content of graduate programs offered there. A review of the recruitment process for graduate RNs entering the aged care sector is required to ensure that health care agencies are targeting those who have an interest in aged care. There is a dearth of research into the recruitment process of graduate RNs, and further study into how they are recruited into the various work areas in their graduate year is warranted. This may assist health care agencies to more appropriately allocate graduate RNs to work areas. From the findings of this study, the recommendation would be that the recruitment of graduate RNs into the aged care area should where possible be matched with the individual's desire to work in the area.

The provision of a standardised aged care graduate program may assist in providing greater consistency in the level of support for all graduate RNs across a variety of aged care workplaces. A graduate program that focuses specifically on the specialist needs of residents in aged care and the specialist role of the RN may assist new graduates to consider aged care as a more satisfying career option. It also appears that an important component of a standardised graduate program in aged care would be the availability of support in the form of a specialist aged care nurse or educator.

Clear guidelines on the role of the graduate RN need to be generated to avoid role confusion for all staff working in the aged care area. The findings suggest that at present some aged care facilities do not have an adequate understanding of the graduate RN role. This appears to have impacted negatively on the study participants' experiences and their own understandings of aged care. A clearer definition of this role may assist aged care agencies to delegate more appropriate nursing tasks and responsibilities.

Limitations

This study was limited to one group of female graduate RNs working in aged care facilities within metropolitan and regional Victoria in 2006. This study consisted of all female participants and therefore, the findings cannot necessarily be extrapolated to the experience of male graduate RNs.

Generalisability is not an aim of qualitative research however; the intention behind the case study method is to make theoretical rather than empirical generalisations (Yin, 2003). The depth of information given by participants has provided valuable insights into graduate RNs' experiences of working in aged care. The use of phone interviews precluded non-verbal cues available in face-to-face encounters that might have given rise to a greater depth of data. A particular strength, the thick descriptions of graduate RNs' experiences and the rigorous methodology that was employed in this study increase the trustworthiness and transferability of this study's findings to other contexts.

\section{CONCLUSION}

This paper reports on the findings of eleven graduate RNs' experiences of working in aged care in Victoria, Australia. This study provides rich ideas relevant to the development of strategies to improve the recruitment and retention of graduate RNs into this sector. The intersection between the lack of interest in working in aged care amongst nurses and the growing needs of an ageing population with more complex needs make this study particularly timely and relevant. The findings provide important new knowledge and insights into the experiences of graduate RNs working in aged care facilities, of particular relevance to those involved in their recruitment and retention.

\section{ACKNOWLEDGEMENT}

The authors would like to acknowledge the time, interest and candour of the new graduate RNs who participated.

Received 21 July 2009 Accepted 10 August 2009

References

Aday, R. H., \& Campbell, M. J. (1995). Changes in nursing students' attitudes and work preferences after a gerontology curriculum. Educational Gerontology, 21, 247-260.

Australian Health Workforce Advisory Committee (AHWAC). (2004). The Australian Nursing Workforce--An overview of workforce planning 20012004. Sydney: AHWAC.

Australian Institute of Health and Welfare (AIHW). (2007). Residential aged care in Australia: 2005-2006. A statistical Overview. Canberra: AIHW.

Beanland, C., Schneider, Z., Lo Biondo-Wood, G., \& Haber, J. (1999). Nursing research methods, critical appraisal and utilization. Sydney: Mosby.

Carmel, S., Cwikel, J., \& Galinsky, D. (1992). Changes in knowledge, attitudes, and work preferences following courses in gerontology among medical, nursing, and social work students'. Educational Gerontology, 18(4), 329-342.

Charmaz, K. (1995). Grounded theory. In J. A. Smith, R. Harre, \& L. V. Langenhove (Eds.), Rethinking methods in psychology (pp. 29-49). London: Sage Publications.

Chenitz, W. C., \& Swanson, J. M. (1986). From practice to grounded theory: Qualitative research in nursing. Menlo Park, CA: Addison Wesley Publishing.

Commonwealth Department of Health and Ageing. (2002). Ageing in place: A guide for providers of residential aged care. Canberra: Commonwealth Department of Health and Ageing.

Dellasega, C., \& Curriero, F. C. (1991). The effects of institutional and community experiences on nursing students' intentions toward work with the elderly. Journal of Nursing Education, 30, 405-410.

Elderkin, T. D. (2005). Retention of critical care course graduates: A regional perspective. Australian Critical Care, 18(3), 114-122.

Fagerberg, I., Ekman, S. L., \& Ericsson, K. (1997). Two studies of the new nursing education in Sweden: 1. The place of gerontology and geriatrics. 2. Student characteristics and expectations. Nurse Education Today, 17(2), 150-157.

Greenhill, E. D., \& Baker, M. F. (1986). The effects of a well older adult clinical experience on students' knowledge and attitudes. Journal of Nursing Education, 25, 145-147.

Happell, B. (1999). When I grow up I want to be a ... ? Where undergraduate student nurses want to work after graduation. Journal of Advanced Nursing, 39(2), 299-505.

Happell, B. (2002). Nursing home employment for nursing students: Valuable experience of a harsh deterrent? Journal of Advanced Nursing, 39, 529536. 
Hayes, L. J., Orchard, C. A., Hall, L. M., Nincic, V., O'Brien-Pallas, L., \& Andrews, G. (2006). Career intentions of nursing students and new RN graduates: A review of the literature. International Journal of Nursing Education Scholarship, 3(1), 26-28.

Holloway, I., \& Wheeler, S. (2002). Qualitative research in nursing (2nd ed.). Oxford: Blackwell Science.

Karmel, T., \& Li, J. (2002). National review of nursing education: The nursing workforce--2010, Department of Education Science and Technology (DEST), Commonwealth of Australia. Retrieved January 12, 2009, from http://www.dest.gov.au/archive/highered/ nursing/pubs/nursing_worfforce_2010/nursing__workforce_default.htmAugust 2002

Lincoln, Y. S., \& Guba, E. G. (1985). Naturalistic inquiry. Newbury Park, CA: Sage Publications.

Lofland, J., \& Lofland, L. H. (1984). Analyzing social settings. Belmont, CA: Wadsworth.

Lookinland, S., \& Anson, K. (1995). Perpetuation of Ageist attitudes among present and future health care personnell: Implications for elder care. Journal of Advanced Nursing, 21(1), 47-56.

Moyle, W. (2003). Nursing students' perception of older people: Continuing society's myths. Australian Journal of Advanced Nursing, 20(4), 15-21.

Moyle, W., \& Kellett, U. (1996). Strategies to overcome the educational challenges in aged care. Geriaction Journal, 14 (3), 14-18.

Nielsen, C. (1999). Meeting the needs of the graduate nurse in aged care. Australian Nursing Journal, 6(7), 30.

Palese, A., Tosatto, D., Borghi, G., \& Maura, M. (2007). Factors influencing the choice of the first ward: Comparison between newly qualified RNs and managers. Journal of Nursing Management, 15, 59-63.

Parliament of Australia Senate. (2002). Report on the inquiry into nursing--The patient profession: Time for action--1 June 2002. Canberra: Parliament of Australia Senate.

Payne, S., Field, D., Rolls, L., Hawker, S., \& Kerr, C. (2007). Case study research methods in end-of-life studies. Journal of Advanced Nursing, 58(3), 236-245.

Pearson, A. (2003). Multidisciplinary nursing: Re-thinking role boundaries. Journal of Clinical Nursing, 12(5), 625-629.

Pearson, A., Nay, R., Koch, S., Ward, C., Andrews, C., \& Tucker, A. (2001). Australian aged care nursing: A critical review of education, training, recruitment and retention in residential and community settings. Canberra: Department of Education, Science and Training.

Polit, D. F., \& Beck, C. T. (2006). Essentials of nursing research: Methods, appraisal, and utilization. Philadelphia: Lippincott.

Post Graduate Medical Council of Victoria. (2003). The computer matching process. Retrieved July 19, 2007, from http://computermatching. pmcv.com.au/public/about/matchingprocess.cfm

Press, N. (2005). Qualitative research: Thoughts on how to do it; how to judge it; when to use it. Genetics in Medicine, 7(3), 155-158.

Richardson, S., \& Martin, B. (2004). The care of older Australians--A picture of residential aged care workforce. Adelaide: The National Institute of Labour Studies, Flinders University.

Ring, N. (2002). A personal and historical investigation of the career trends of UK graduate nurses qualifying between 1970 and 1989 . Journal of Advanced Nursing, 40(2), 199-209.

Robinson, A., \& Cubit, C. (2007). Caring for older people with dementia in residential care: Nursing students' experiences. Journal of Advanced Nursing, 59(3), 255-263.

Rushforth, H., \& Glasper, E. A. (1999). Implications of nursing role expansion for professional practice. British Journal of Nursing, 88(22), 1507-1513.

Senate Community Affairs References Committee. (2005). Quality and equity in aged care. Retrieved July 28, 2008, from http://www.aph. gov.au/senate/committee/clac_ctte/aged_care04/ report/report.pdf

Stevens, J., \& Crouch, M. (1995). Who cares about care in nursing education? International Journal of Nursing Studies, 32(3), $233-242$.

Stevens, J., \& Dulhunty, G. (1992). New South Wales nursing students' attitudes towards a career in mental health. Australian Journal of Mental Health Nursing, 2(2), 59-64.

Strauss, A., \& Corbin, J. (1990). Basics of qualitative research: Grounded theory procedures and techniques. Newbury Park: Sage Publications.

Victorian Government Department of Human Services, Nurse Policy Branch. (2003). Graduate nurse program guidelines--2003. Melbourne: Nurse Policy Branch Victorian Government Department of Human Services.

Walshe, C. E., Caress, A. L., Chew-Graham, C., \& Todd, C. (2005). Case studies: A research strategy appropriate for palliative care? Palliative Medicine, 18, 677-684.

Yin, R. K. (2003). Case study research: Design and methods. London: Sage Publications.

BRIDGET FUSSELL

Lecturer, School of Nursing and Midwifery (Victoria), Faculty of Health Sciences, Australian Catholic University, Melbourne, VIC, Australia FRAN MCINERNEY

Associate Professor, Aged Care, Joint Appointment Catholic Homes/ACU National, School of Nursing \& Midwifery (Victoria), Faculty of Health Sciences, Australian Catholic University, Melbourne, VIC, Australia 


\section{ELIZABETH PATTERSON}

Head, School of Nursing and Midwifery, Gold Coast Campus, Griffith University, Brisbane, QLD, Australia

TABLE 1 : CHARACTERISTICS OF THE SAMPLE

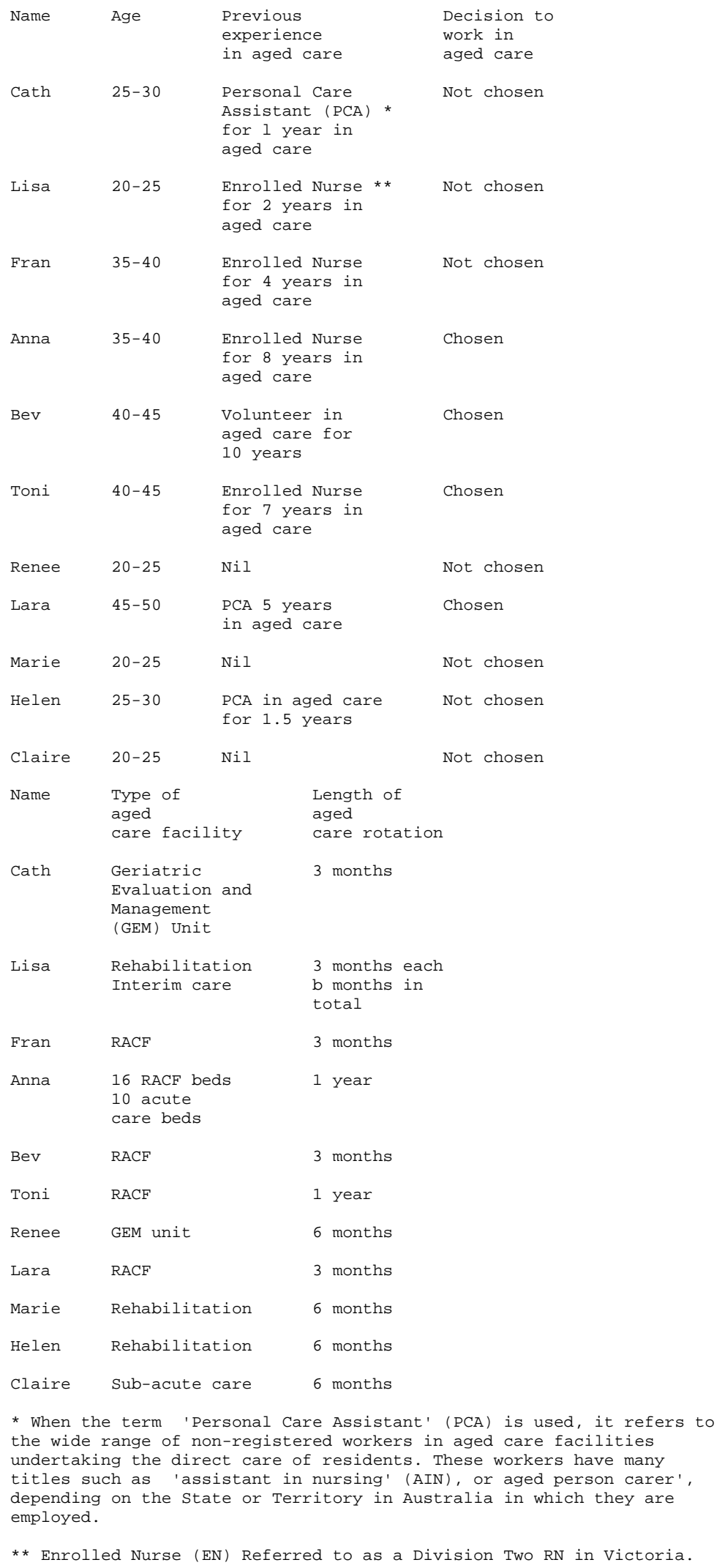

Gale Document Number:A214205455

Disclaimer: This information is not a tool for self-diagnosis or a substitute for professional care. 